\title{
Genomic Insight Into the Predominance of Candidate Phylum Atribacteria JS1 Lineage in Marine Sediments
}

\begin{abstract}
Yung Mi Lee', Kyuin Hwang 1,2, Jae II Lee, Mincheol Kim', Chung Yeon Hwang', Hyun-Ju Noh', Hakkyum Choi ${ }^{4}$, Hong Kum Lee', Jongsik Chun ${ }^{5}$, Soon Gyu Hong ${ }^{1 *}$ and Seung Chul Shin ${ }^{* *}$
\end{abstract}

${ }^{1}$ Division of Polar Life Sciences, Korea Polar Research Institute, Incheon, South Korea, ${ }^{2}$ Department of Polar Science, University of Science and Technology, Daejeon, South Korea, ${ }^{3}$ Division of Polar Paleoenvironment, Korea Polar Research Institute, Incheon, South Korea, ${ }^{4}$ Division of Polar Earth-System Sciences, Korea Polar Research Institute, Incheon, South Korea, ${ }^{5}$ School of Biological Sciences, College of Natural Sciences, Seoul National University, Seoul, South Korea,

${ }^{6}$ Unit of Polar Genomics, Korea Polar Research Institute, Incheon, South Korea

OPEN ACCESS

Edited by:

Julia Kleinteich,

University of Tübingen, Germany

Reviewed by:

Stephanie Ann Carr

Hartwick College, United States

Eric Daniel Becraft,

University of North Alabama,

United States

*Correspondence:

Soon Gyu Hong

polypore@kopri.re.kr

Seung Chul Shin

biotech21@gmail.com

Specialty section:

This article was submitted to

Extreme Microbiology

a section of the journal

Frontiers in Microbiology

Received: 08 July 2018 Accepted: 13 November 2018 Published: 29 November 2018

Citation:

Lee YM, Hwang K, Lee JI, Kim M, Hwang CY, Noh H-J, Choi H, Lee HK, Chun J, Hong SG and Shin SC (2018)

Genomic Insight Into the Predominance of Candidate Phylum Atribacteria JS1 Lineage

in Marine Sediments.

Front. Microbiol. 9:2909.

doi: 10.3389/fmicb.2018.02909
Candidate phylum Atribacteria JS1 lineage is one of the predominant bacterial groups in anoxic subseafloor sediments, especially in organic-rich or gas hydrate-containing sediments. However, due to the lack of axenic culture representatives, metabolic potential and biogeochemical roles of this phylum have remained elusive. Here, we examined the microbial communities of marine sediments of the Ross Sea, Antarctica, and found candidate phylum Atribacteria JS1 lineage was the most abundant candidate phylum accounting for $9.8-40.8 \%$ of the bacterial communities with a single dominant operational taxonomic unit (OTU). To elucidate the metabolic potential and ecological function of this species, we applied a single-cell genomic approach and obtained 18 single-cell amplified genomes presumably from a single species that was consistent with the dominant OTU throughout the sediments. The composite genome constructed by co-assembly showed the highest genome completeness among available Atribacteria JS1 genomes. Metabolic reconstruction suggested fermentative potential using various substrates and syntrophic acetate oxidation coupled with hydrogen or formate scavenging methanogens. This metabolic potential supports the predominance of Atribacteria JS1 in anoxic environments expanding our knowledge of the ecological function of this uncultivated group.

Keywords: candidate division, Atribacteria, JS1, single-cell genomics, Antarctica, Ross Sea, marine sediment

\section{INTRODUCTION}

The subseafloor biosphere, which contains huge amounts of microbial biomass, plays a significant role in biogeochemical cycling and the remineralization of organic materials (Kallmeyer et al., 2012; Parkes et al., 2014). Enormous progress has been made in studies of subseafloor microbes. As a first step toward understanding ecological functions of the subseafloor, many studies have evaluated microbial community structures from a variety of seas and their relationships with physicochemical parameters (Kato et al., 1997; Inagaki et al., 2006; Webster et al., 2006a; Schauer et al., 2009; 
Zinger et al., 2011; Hamdan et al., 2012; Jorgensen et al., 2012; Parkes et al., 2014; Carr et al., 2015; Corinaldesi, 2015; Nunoura et al., 2016). These surveys revealed that the microbial composition is shaped by the physicochemical properties of the environment, including oxygen concentration and nutrient availability (Zinger et al., 2011; Jorgensen et al., 2012; Parkes et al., 2014). The majority of microorganisms belonged to unidentified and uncultured phyla, making it difficult to infer their metabolic activities and ecological functions (Handelsman, 2004; Webster et al., 2004; Inagaki et al., 2006; Orcutt et al., 2011; Rinke et al., 2013; Macaulay and Voet, 2014; Corinaldesi, 2015; Eloe-Fadrosh et al., 2016; Nobu et al., 2016). Thus, understanding the metabolism and functions of candidate divisions in the subseafloor biosphere is a major challenge and will provide substantial insights into the roles of microbes in global biogeochemical cycles.

Candidatus (Ca.) Atribacteria is a candidate phylum that was proposed (Nobu et al., 2016) to include members of the OP9 (Hugenholtz et al., 1998) and JS1 (Rochelle et al., 1994; Webster et al., 2004) lineages. The JS1 lineage is a predominant bacterial group in subseafloor sediments, especially in some strictly anoxic organic-rich environments or gas hydrate-containing sediments, and methanogenic meromictic lakes (Webster et al., 2004, 2006a; Inagaki et al., 2006; Orcutt et al., 2011; Gies et al., 2014; Parkes et al., 2014; Carr et al., 2015; Ruff et al., 2015; Nobu et al., 2016; Nunoura et al., 2016; Saxton et al., 2016). To elucidate the physiology of the JS1 lineage, culture-independent approaches such as isotope enrichment studies and genomics have been applied (Webster et al., 2006b, 2011; Dodsworth et al., 2013; Lloyd et al., 2013; Rinke et al., 2013; Carr et al., 2015; Nobu et al., 2015, 2016). Stable isotope probing and enrichment studies revealed the incorporation of acetate and glucose into members of JS1, suggesting heterotrophic metabolism (Webster et al., 2006b, 2011). Single-cell amplified genome (SAG) analysis or metagenomic approaches to marine sediments from Aarhus Bay, Etoliko Lagoon, and the Adélie Basin, biofilms from a terephthalate-degrading reactor, and monimolimnion of the meromictic Sakinaw Lake also indicated that members of JS1 are heterotrophic anaerobes that lack respiratory capacity (Dodsworth et al., 2013; Lloyd et al., 2013; Rinke et al., 2013; Carr et al., 2015; Nobu et al., 2016). The high-coverage JS1 genomes recovered from meromictic Sakinaw Lake and the mesophilic bioreactor revealed the capacity to catabolize organic acids such as propionate and acetate via the methylmalonylCoA pathway and lack of sugar fermentation pathways (Nobu et al., 2016). However, the low-coverage JS1 genomes from marine sediments $(<22 \%)$ did not allow detailed description of metabolic potential in spite of the predominance of JS1 in those environments and, thus, the metabolism and ecological functions of the JS1 lineage in marine sediments remain largely unknown (Lloyd et al., 2013; Rinke et al., 2013; Carr et al., 2015; Nobu et al., 2015, 2016).

In this study, we investigated the vertical profiles of bacterial and archaeal communities along a 3.96-m-long sediment core in the Ross Sea, Antarctica, using 454 pyrosequencing of $16 \mathrm{~S}$ rRNA genes and found that the JS1 lineage was the predominant bacterial group throughout the sediments below the surface.
Given the dearth of genomic information on the JS1 lineage from marine sediments, we analyzed single-cell genomes of the JS1 lineage to understand the metabolic potential and assess their ecological role in the environment.

\section{MATERIALS AND METHODS}

\section{Sampling and Handling}

Sediment samples were collected from a 3.96-m gravity core (DG12-GC06) retrieved from the western Ross Sea, Antarctica $\left(75^{\circ} 39.5684^{\prime} \mathrm{S}, 165^{\circ} 23.8382^{\prime} \mathrm{E}\right.$, water depth $\left.859 \mathrm{~m}\right)$, on January 15,2012 , on the research vessel (RV) ARAON. The entire round core was cut in half, and samples were collected with a sterile (autoclaved) spatula at $20-\mathrm{cm}$ intervals, including the surface (Lee, 2017). Samples for molecular biological analysis were stored untreated at $-80^{\circ} \mathrm{C}$ and those for recovery of single cells were suspended in $20 \%$ glycerol (v/v) and stored at $-80^{\circ} \mathrm{C}$ until analysis. Water content, grain size distribution, total nitrogen content and total organic carbon content of samples were analyzed. The content of particles larger than sand-size was determined by wet sieving, and the content of silt- and clay-sized particles was analyzed using a Micrometric Sedigraph 5120. Contents of total nitrogen (TN) and total carbon (TC) were analyzed using a Flash EA 1112 element analyzer and the analytical precisions are within $\pm 0.02 \%$ for $\mathrm{TN}$ and $\pm 0.1 \%$ for TC. Total organic carbon (TOC) content was determined by subtracting total inorganic carbon from total carbon content. Total inorganic carbon content was analyzed for a $2 \mathrm{~N} \mathrm{HCl}$-dissolved portion using a UIC 5030 coulometer.

\section{Genomic DNA Extraction and Amplification}

Genomic DNA was extracted from approximately $0.5 \mathrm{~g}$ of sample using a FastDNA Spin Kit for Soil (Qbiogene, Carlsbad, CA, United States). The 16S rRNA gene was amplified by polymerase chain reaction (PCR) using primers 27F (Lane, 1991)/518R (Kato et al., 1997) and 8F (3'-CTCAGAGTAGTCCGGTTGATCCYGCCGG-5')/519R (3'-ACAGAGACGAGGTDTTACCGCGGCKGCTG-5') with barcodes for bacterial and archaeal community analysis, respectively. PCR was carried out with $30 \mu \mathrm{L}$ reaction mixtures containing $2 \times$ Dream Tag Green PCR master mix (Thermo Fisher Scientific, Waltham, MA, United States), $1 \mu \mathrm{M}$ each primer, and approximately $10 \mathrm{ng}$ of genomic DNA. The PCR procedure included an initial denaturation step at $94^{\circ} \mathrm{C}$ for $3 \mathrm{~min}, 30$ cycles of amplification $\left(94^{\circ} \mathrm{C}\right.$ for $1 \mathrm{~min}, 55^{\circ} \mathrm{C}$ for $1 \mathrm{~min}$, and $72^{\circ} \mathrm{C}$ for $1.5 \mathrm{~min}$ ), and a final extension step at $72^{\circ} \mathrm{C}$ for $5 \mathrm{~min}$. Each sample was amplified in triplicate and pooled. PCR products were purified using a LaboPass purification kit (Cosmogenetech, Seoul, South Korea). Because of PCR failure for samples below $120 \mathrm{~cm}$ below the sea floor (cmbsf) with archaeal primers, these samples were not included in further analyses. For the bacterial community in the 140 and $320 \mathrm{cmbsf}$ samples, barcodes were overlapped and thus these samples were excluded from further analysis. 


\section{Analysis of Microbial Community}

Sequencing of amplicons was carried out by Chun Lab (Seoul, South Korea) using a 454 GS FLX sequencer (Roche, Branford, CT, United States). Preprocessing was conducted using PyroTrimmer (Oh et al., 2012). Sequences were processed to remove primer, linker, and barcode sequences. The $3^{\prime}$-ends of sequences with low quality values were trimmed when average quality scores for a 5-bp window size were $<20$. Sequences with ambiguous nucleotides or $<200 \mathrm{bp}$ were discarded. Sequence clustering was performed by CLUSTOM (Hwang et al., 2013) with a 97\% similarity cutoff. Chimeric reads were detected and discarded using the de novo chimera detection algorithm of UCHIME (Edgar et al., 2011). Taxonomic assignment for representative sequences of the bacterial and archaeal OTUs was conducted using an EzTaxon-e database search (Kim et al., 2012). Prefix "B_" for bacterial OTUs and "A_" for archaeal OTUs were attached. The habitats of archaeal sequences were inferred by matching OTU representative sequences to those in the GenBank database using a BLAST search with $\geq 97 \%$ sequence similarity cutoff.

\section{Statistical Analysis}

The relative similarities of bacterial and archaeal communities among samples were calculated by Bray-Curtis similarity using an OTU abundance matrix prepared by logarithmic transformation of percent abundance +1 by PRIMER v6 (Clarke and Gorley, 2006). Spearman correlations between the major JS1 OTU, designated B_OTU1, and major archaeal OTUs ( $\geq 3 \%$ in relative abundance) were performed using the $\mathrm{R}$ package to find significant relationships.

\section{Single-Cell Sorting, Genome Amplification, Sequencing, and Phylogenetic Analysis}

Based on bacterial community results, a sample from $40 \mathrm{cmbsf}$ which harbored $39.6 \%$ JS1 was selected for single-cell sorting. Samples preserved in $20 \%$ glycerol at $-80^{\circ} \mathrm{C}$ were centrifuged for $1 \mathrm{~min}$ at $9,300 \times g$ and $0.5 \mathrm{~mL}$ of the supernatant was mixed with $100 \mu \mathrm{L}$ of $100 \times \mathrm{TE}$ buffer $(\mathrm{pH}$ 8.0) and $5 \mathrm{~mL}$ of filtered and autoclaved seawater, packed in dry ice, and sent to Bigelow Lab (East Boothbay, ME, United States). Physical isolation of single cells was performed by fluorescentactivated cell sorting in a 384-well plate. After single-cell sorting, lysis of single cells and amplification of the singlecell genome by multiple displacement amplification (MDA) were performed. MDA product subsamples were used as a template in PCR for amplification of bacterial $16 \mathrm{~S}$ ribosomal RNA genes using the primer sets 27F and 1492R (Lane, 1991). Eighteen SAGs belonging to the JS1 lineage were sequenced using a MiSeq sequencer system (Illumina) at Chun Lab. For phylogenetic analysis of JS1 lineage, 16S rRNA gene sequences from this study were aligned with those of JS1 retrieved from the SAGs and metagenomic data sets (Table 1) and two dominant OTUs of the JS1 lineage, B_OTU1 and B_OTU3, obtained from pyrosequencing results (Supplementary File 1) using jPhydit (Jeon et al., 2005). A phylogenetic tree was constructed using maximum-likelihood method based on the general time reversible model (Felsenstein, 1981; Nei and Kumar, 2000) with the gamma distribution with invariant sites using MEGA 6 (Tamura et al., 2013). The robustness of the tree topologies was assessed by bootstrap analyses based on 1,000 replications.

\section{Genome Assembly and Annotation}

Quality trimming and assemblies of sequencing reads were performed using CLC Genomics Workbench (version 8.0). Quality trimming was performed with the parameters "limit $=0.05$ " and "maximum number of ambiguities $=2$. " For assembly, the bubble size and word size was set to 50 and 22 , respectively. A read mapping was performed after the initial contig creation and contig regions with no reads map were removed. Average nucleotide identity (ANI) values of 18 SAGs were calculated to identify whether the SAGs were identical to each other using the dnadiff script of the MUMmer tool (version 3.0) (Kurtz et al., 2004). To construct the composite SAG (cSAG), designated RS JS1-cSAG, reads from 18 SAGs were pooled and assembled. Assembled contigs were annotated with Rapid Annotation using Subsystem Technology (RAST) (Aziz et al., 2008). Additional enzyme commission (EC) numbers for coding sequences were obtained from the KEGG Automatic Annotation Server (KAAS) (Moriya et al., 2007).

\section{Genome Completeness Estimation}

Genome completeness was estimated using the Conserved Single Copy Gene (CSCG) set (bacteria: 139 markers), as previously described by Rinke et al. (2013). To identify CSCGs in the RS JS1cSAG, protein sequences for PFAM matches were analyzed (Finn et al., 2016). The search for protein families using HMMER3 was performed using an online tool ${ }^{1}$. Proteins with the resulting best hits above precalculated HMM cutoffs were selected as CSCGs, and the completeness was estimated as the ratio of CSCGs detected to total CSCGs. Since the CSCGs were defined to occur only once in at least $90 \%$ of all genomes $(n=1,516)$, the number of total CSCGs was normalized to $90 \%$ (Rinke et al., 2013). CheckM was also used for estimation of genome completeness and contamination using their domain-specific markers (bacteria: 104 markers) (Parks et al., 2015).

\section{Nucleotide Sequence Accession Numbers}

Sequences obtained by pyrosequencing technology have been deposited in the Short Read Archive of the National Center for Biotechnology Information under accession numbers 66606576660675 under the BioProject number PRJNA380995. RS JS1cSAG sequences have been deposited in the Whole-Genome Shotgun project at DDBJ/EMBL/GenBank under accession number NCRO00000000, and the annotated assemblies for the RS JS1-cSAG (Genome ID 6666666.379707) are available at RAST $^{2}$ by logging in with a guest account (username and

\footnotetext{
${ }^{1}$ http://pfam.xfam.org/

${ }^{2} \mathrm{http}: / /$ rast.nmpdr.org/
} 


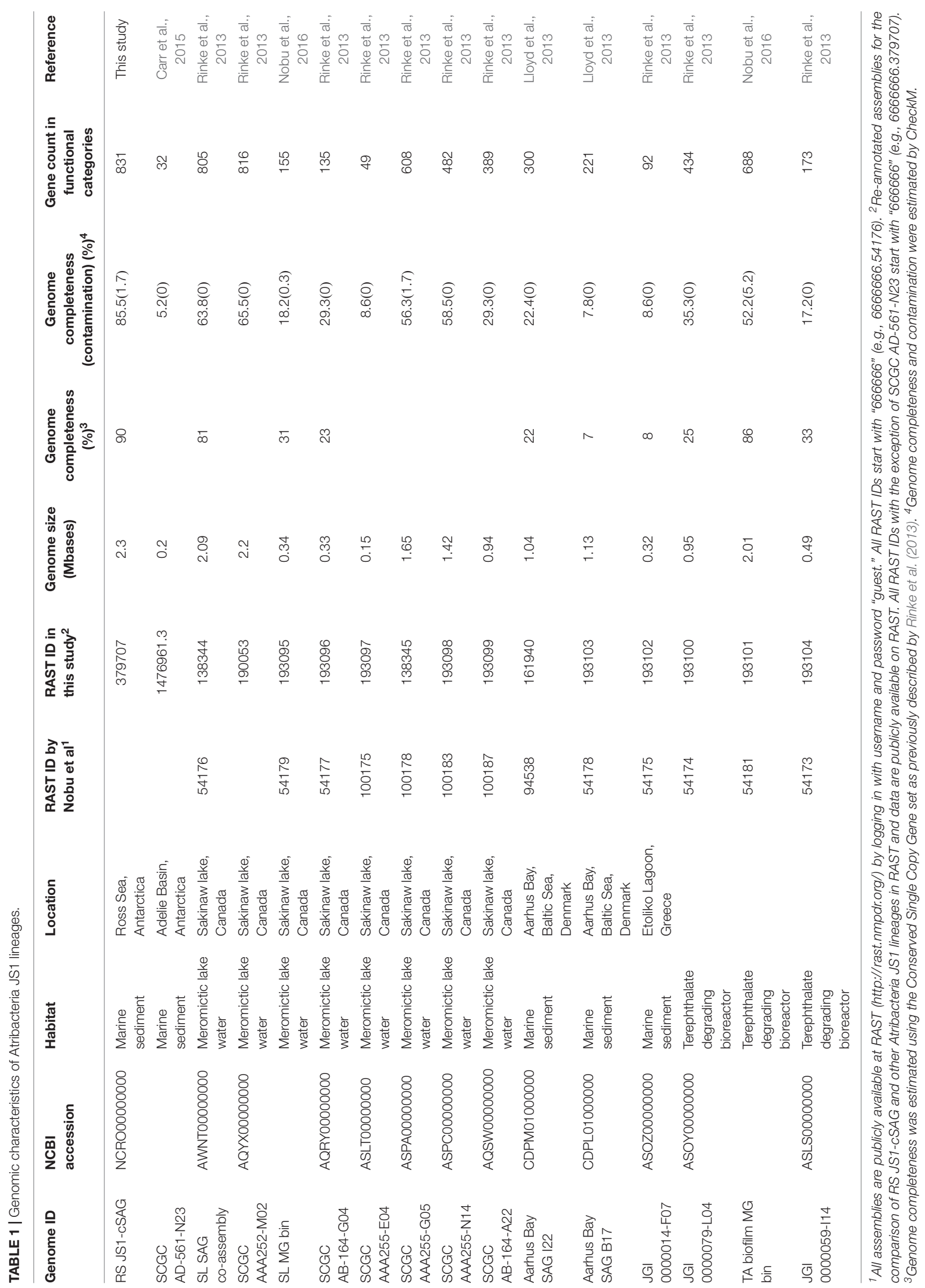


A

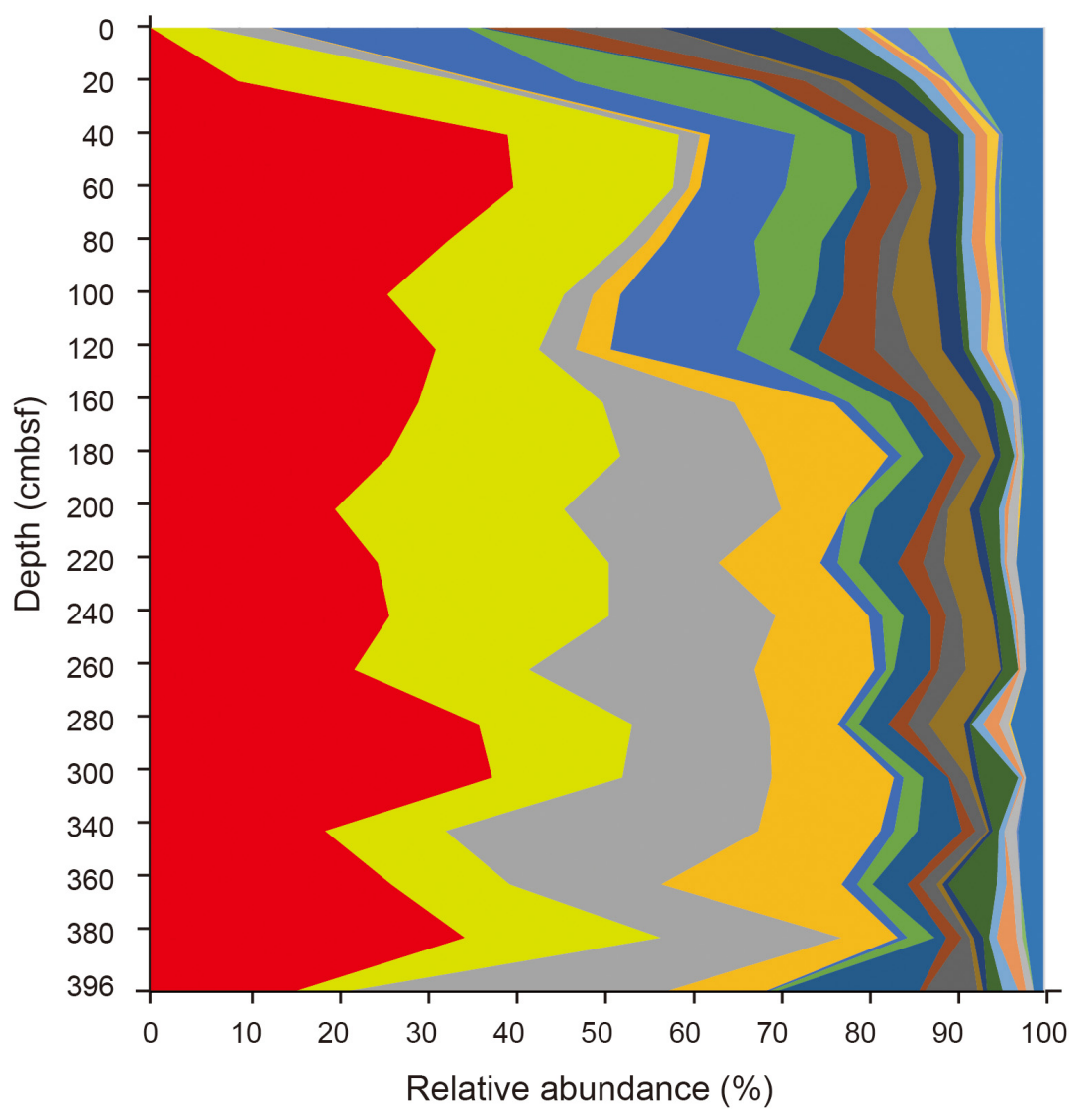

Ca. Atribacteria JS1

Chloroflexi

- Actinobacteria

- Betaproteobacteria

- Alphaproteobacteria

- Aminicenantes_OP8

- Firmicutes

- Planctomycetes

- Gammaproteobacteria

- Aerophobetes_CD12

- Deltaproteobacteria

- Bacteroidetes

- Bacteria_unclassified

- Parcubacteria_OD1

DQ513075_p

1. TM6

- Acidobacteria

- Chlorobi

- Others

B

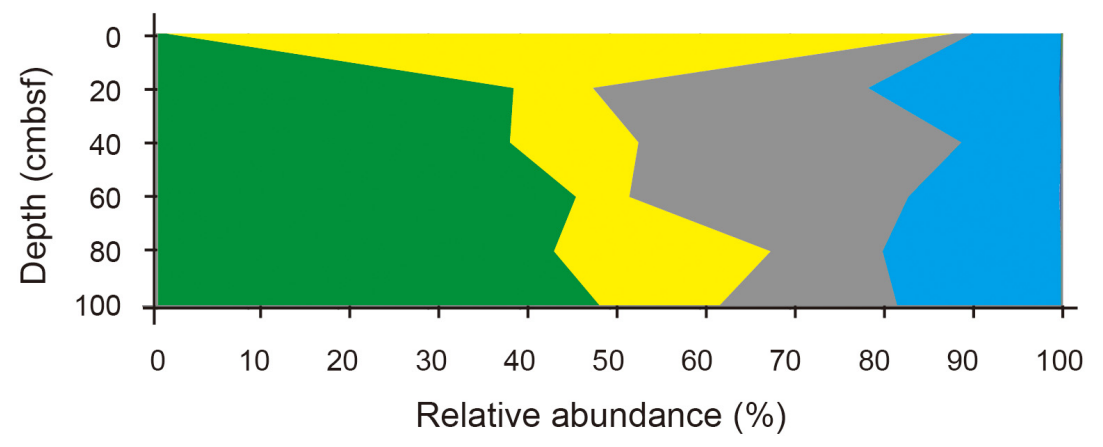

Lokiarchaeota

Thaumarchaeota

Euryarchaeota

Crenarchaeota

AAG

unclassified

FIGURE 1 | Relative abundance of sequenced bacterial (A) and archaeal communities (B) at the phylum level or the class level in the case of Proteobacteria along the depth of the core.

password = "guest"). The $16 \mathrm{~S}$ rRNA sequences were submitted to NCBI GenBank under accession numbers KY888007-KY888024.

\section{RESULTS}

\section{Environmental Factors of Sediments}

The amount of TN, TOC, and water in the core varied according to the lithologic characteristics of the sediment (Supplementary Figure S1). The core can be divided into three units: the upper unit of greenish-gray diatomaceous mud with minor ice-rafted debris (core depth: $0-120 \mathrm{cmbsf}$ ); the middle unit of dark greenish-gray to dark gray diamicton and sandy mud (120-360 cmbsf); and the lower unit of light greenish-gray diatomaceous mud (360-396 cmbsf). Clay- and silt-sized grains were dominant throughout the core, but the content of coarsersized grains (sands and gravels) reached up to $20 \%$ in the middle unit. Water content of the upper unit sediment (63$64 \mathrm{wt} . \%)$ was much higher than that of the middle and lower unit sediments ( $\sim 30$ wt.\%) (Supplementary Figure S1), which 


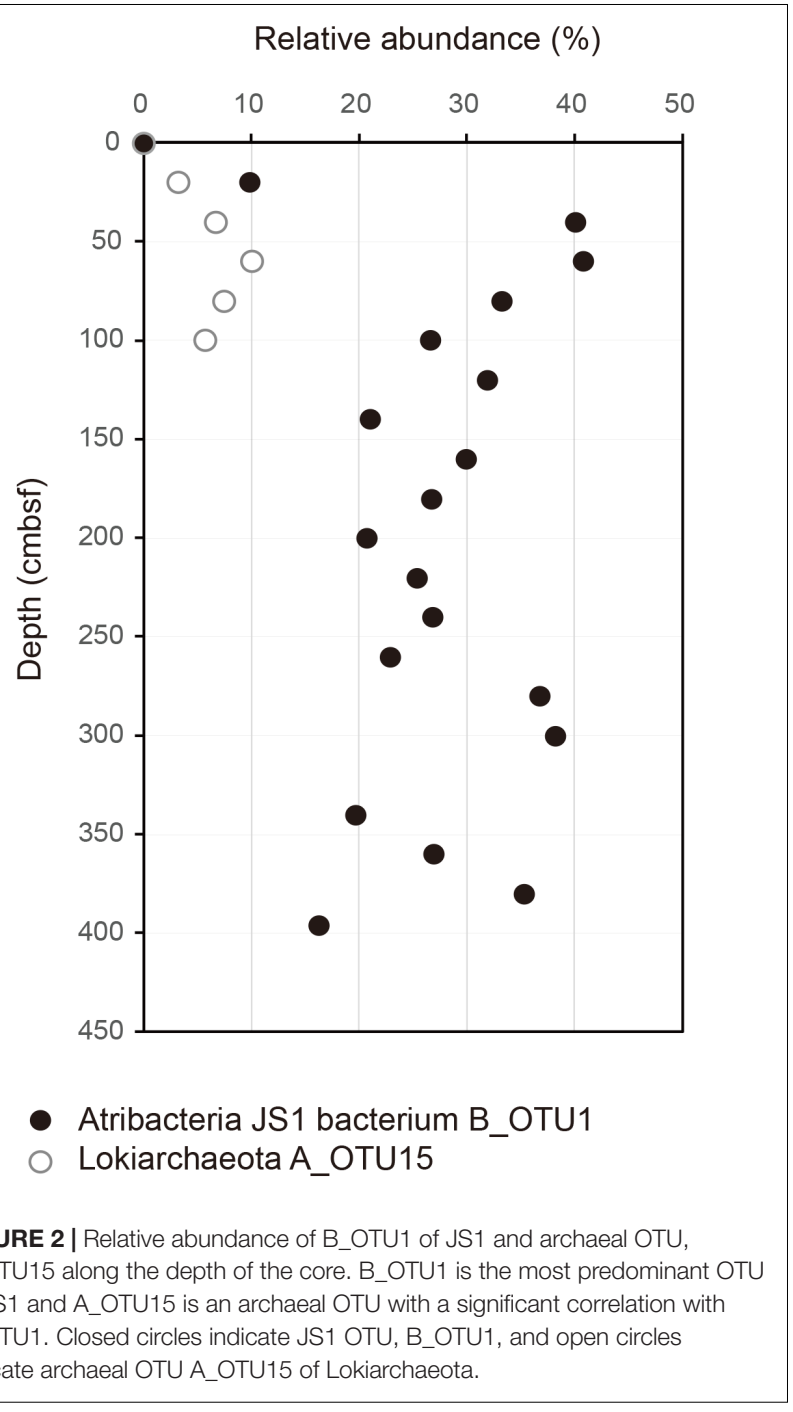

can be attributed to differences in grain size distribution and depositional setting. TOC content was generally low ( $<1 \mathrm{wt} . \%$ throughout the core) (Supplementary Figure S1). Contents of TOC and TN were higher in the upper unit than in the lower units (Supplementary Figure S1), which may be related to higher primary production during postglacial periods than glacial periods.

\section{Depth Profile of Microbial Phyla and Major OTUs}

Relative abundances of the sequenced bacterial phyla showed stratification along the depth of the core (Figure 1A) and bacterial community composition was clustered into three groups: 0 cmbsf, 20-120 cmbsf, and 160-393 cmbsf (Supplementary Figure S2A). In surface sediment, Alphaproteobacteria (21.9\%), Deltaproteobacteria (12.1\%), Gammaproteobacteria (11.0\%), Planctomycetes (8.6\%), Bacteroidetes (7.7\%), Actinobacteria (7.0\%), Chlorobi (4.7\%), and Acidobacteria (4.2\%) were more abundant, whereas
Ca. Atribacteria JS1 (9.8-40.8\%), Chloroflexi (6.0-26.0\%), Actinobacteria (1.9-35.6\%), Betaproteobacteria (0.5-20.1\%) and Aminicenantes (1.0-19.5\%) were found in higher abundance at and below $20 \mathrm{cmbsf}$. Ca. Atribacteria JS1 and Chloroflexi dominated throughout the subsurface sediments, accounting for 22.2 to $59.2 \%$ of bacterial communities. Notably, a single OTU, B_OTU1, accounted for a high proportion of the sequenced JS1 lineage (9.1-40.1\%) at and below $20 \mathrm{cmbsf}$ (Figure 2). Relative abundance of Aminicenantes was higher from 20 to $160 \mathrm{cmbsf}$, while the relative abundance of Actinobacteria and Betaproteobacteria was distinctively higher at and below 160 cmbsf than in the upper sediments (Figure 1A).

Archaeal phyla detected throughout the sediments included Lokiarchaeota (formerly Marine Benthic Group B), Thaumarchaeota, Euryarchaeota, Crenarchaeota, and ancient archaeal group (AAG) (Figure 1B). Like the bacterial communities, archaeal communities were clearly divided at 20 cmbsf (Supplementary Figure S2B). In the surface sediment, Thaumarchaeota was the most dominant archaeal phylum, accounting for $87 \%$ of the sequenced archaeal community. However, in sediments at and below $20 \mathrm{cmbsf}$, candidate division Lokiarchaeota was the most abundant group, accounting for $39.1-48.9 \%$ of the sequenced archaeal community, followed by Euryarchaeota (12.3-35.9\%) and Crenarchaeota (10.9-21.2\%). Major archaeal OTUs with proportions of $>3 \%$ in each sample also clearly changed along the depth (Supplementary Figure S3). Four OTUs of Thaumarchaeota accounted for $86.5 \%$ of the archaeal community at the surface, whereas their abundance at and below $20 \mathrm{cmbsf}$ ranged from 5.9 to 23.5\% (Supplementary Figure S3). Notably, two OTUs of Lokiarchaeota, A_OTU2 and A_OTU15, with proportions of 1.0 and $0.0 \%$, respectively, at $0 \mathrm{cmbsf}$ increased to 38.8 and $10 \%$, respectively, in deeper sediments. The Euryarchaeota, OTU A_OTU5, which was rarely recovered at $0 \mathrm{cmbsf}$, accounted for $25.5 \%$ at $40 \mathrm{cmbsf}$.

To investigate the co-occurrence of the single dominant OTU of the JS1 lineage (B_OTU1) and major archaeal OTUs ( $\geq 3 \%$ relative abundance), Spearman correlation coefficients were calculated. B_OTU1 of JS1 was positively correlated with A_OTU15 of Lokiarchaeota $(r=0.94, p<0.01)$ (Supplementary Table S1 and Figure 2). The low 16S rRNA gene similarity of the archaeal OTUs that showed significant correlations did not allow them to be assigned to any known taxa (Supplementary Figure S3). To infer the ecophysiological properties of archaeal OTU, A_OTU15, which had a significant positive correlation with major JS1 OTU (B_OTU1), the habitats of sequences with $>97 \%$ similarity with A_OTU15 were recovered and analyzed. Most of the sequences recovered were from marine sediments, and particularly from gas-hydrate bearing sediments, cold or hydrocarbon seeps, or mud volcanoes (Supplementary Table S2).

\section{Genome Characteristics of Single Amplified Genomes and Phylogenetic Diversity of JS1 Lineage}

Eighteen SAGs of the JS1 lineage from a sediment sample (40 cmbsf) were recovered by single-cell sorting and genome 


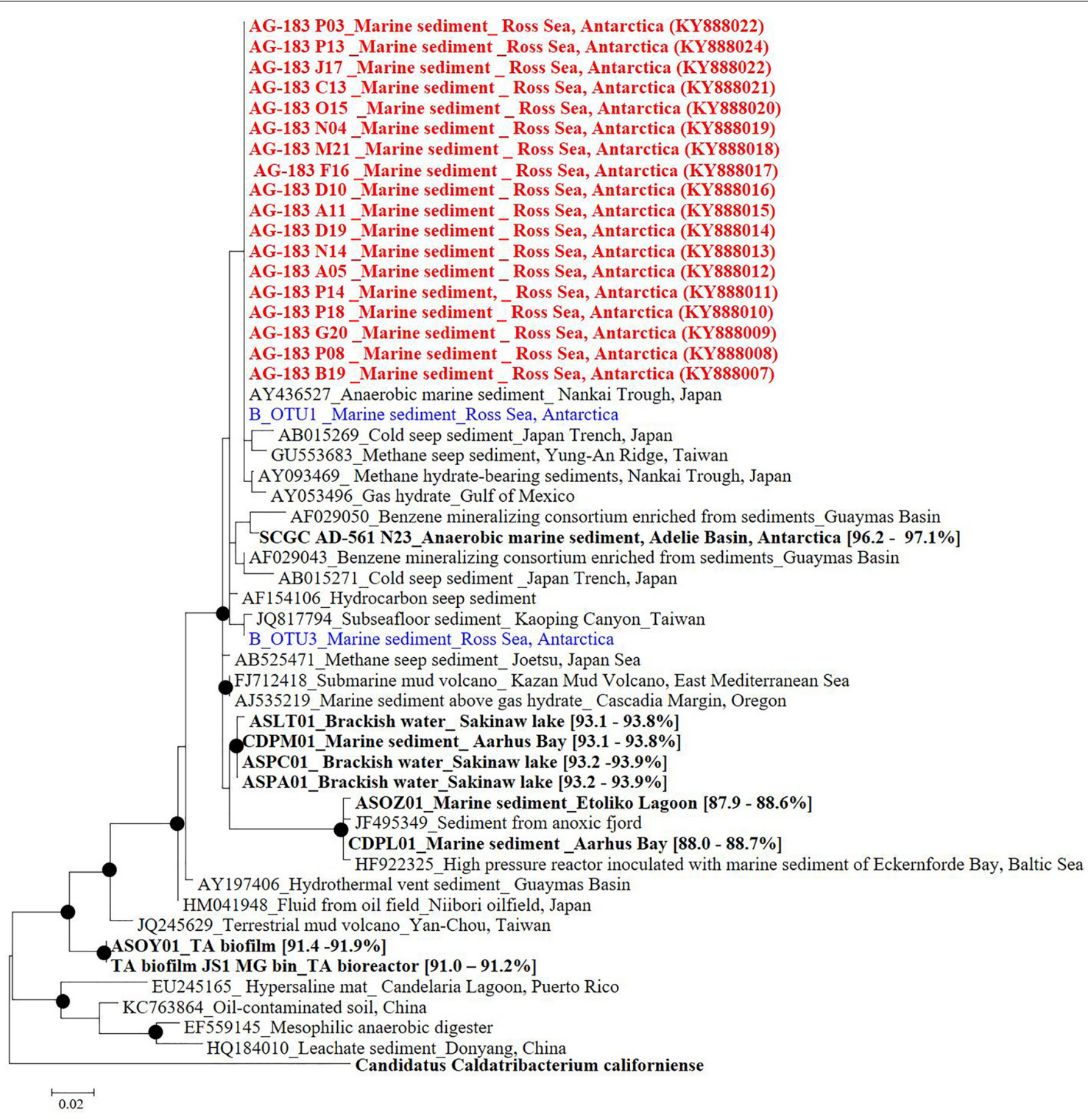

FIGURE 3 | Phylogenetic tree based on 16S rRNA gene sequences from Candidatus Atribacteria JS1 lineage. Red colored sequences represent sequences retrieved from single-cell genomes obtained in this study while blue colored sequences were obtained by pyrosequencing of $16 \mathrm{~S}$ rRNA amplicons in this study. B_OTU1 and B_OTU3 were the most abundant Ca. Atribacteria JS1 sequences. Sequences from other studies are indicated with GenBank accession ID numbers, the habitats, and location of the organisms from which the sequences were obtained. Bold sequences were obtained from single-cell genomes or metagenomes and values in parentheses are the 16S rRNA gene sequence similarity with those from single-cell genomes obtained in this study. Filled circles indicate that the corresponding nodes had $>70 \%$ bootstrap values based on 1,000 resamplings. Ca. Caldatribacterium californiense that belongs to the OP9 lineage of Atribacteria was used as an outgroup.

amplification. The size of each SAG ranged from 300 to $894 \mathrm{~kb}$ (Supplementary Table S3). The SAGs shared 16S rRNA gene sequence similarity $\geq 99.4 \%$ and had $>99.5 \% 16 \mathrm{~S}$ rRNA gene sequence similarity with B_OTU1, the most predominant JS1 OTU at this site (Supplementary Table S4). When 16S rRNA gene sequences from this study were compared with those retrieved from JS1 genomes from other habitats, SCGC_AD561_N23 from the Adélie Basin offshore Antarctica showed the highest similarity (96.2-97.1\%), followed by ASPA from Sakinaw Lake (93.2-93.9\%) (Table 1 and Supplementary Table S4).
Phylogenies inferred from 16S rRNA gene sequences revealed that the JS1 lineage obtained in this study formed a monophyletic clade (Figure 3). The ANI values between overlapping regions of the SAGs ranged from 96.8 to $99.9 \%$, with an average of $99.2 \%$ per SAG (Supplementary Table S5), and this level was above the ANI cut-off value (95-96\%) proposed for delineating bacterial species (Goris et al., 2007; Richter and Rosselló-Móra, 2009). In contrast, the ANI values between the SAGs in this study and JS1 genomes from other habitats ranged from 84.3 to 93.9\% (Supplementary Table S5). Based on the high 16S rRNA 
TABLE 2 | Assembly statistics and genomic features of RS JS1-cSCG.

\begin{tabular}{|c|c|}
\hline General features & RS JS1-cSCG \\
\hline Assembly size (bp) & $2,233,071$ \\
\hline No. of contigs & 698 \\
\hline Contig N50, bases & 5,234 \\
\hline Largest contig bases & 32,879 \\
\hline $\mathrm{G}+\mathrm{C}$ content $(\%)$ & 34.8 \\
\hline Protein coding genes & 2,189 \\
\hline Function assigned & 831 \\
\hline Hypothetical & 645 \\
\hline rRNA genes & $5 S(1), 16 S(2)$, and $23 S(2$ \\
\hline tRNA genes & 37 \\
\hline Genome completeness ${ }^{1}$ & $90.32 \%$ \\
\hline Genome completeness/contamination ${ }^{2}$ & $85.5 \% / 1.7 \%$ \\
\hline
\end{tabular}

${ }^{1}$ Genome completeness was estimated using the Conserved Single Copy Gene set, as previously described by Rinke et al. (2013).

${ }^{2}$ Genome completeness and contamination were estimated using CheckM (Parks et al., 2015).

gene sequence similarities, ANI values and a phylogenetic tree supporting that the 18 SAGs were from a single species, all data sets were co-assembled to construct a cSAG designated RS JS1-cSAG. After the jackknifing procedure to remove chimeric sequences generated during MDA (Marshall et al., 2012), the assembly size was $\sim 2.24 \mathrm{Mb}$, with $34.8 \%$ GC content (Tables 1, 2). The N50 contig size was 5,234 bases, and the largest contig size was 32,879 bases. The number of predicted protein-coding sequences was 2,189, and a total of 831 proteincoding genes were assigned to RAST subsystem categories (Table 2). A total of 113 CSCGs were identified using an HMM search against PFAM databases, and the estimated genome completeness of the RS JS1-cSAG was found to be $90.32 \%$ (Table 2 and Supplementary Table S6). Genome completeness and contamination estimated using CheckM were 85.5 and $1.7 \%$, respectively (Table 2 ).

\section{Genomic Features of RS JS1-cSAG ABC Transporters}

ATP-binding cassette (ABC) transporters are a major class of cellular translocation machinery in all bacterial species and often consist of multiple subunits such as an ATPbinding protein, a membrane protein, and a substrate-binding protein. The RS JS1-cSAG encoded various ABC transporters for amino acids, peptides, oligosaccharides, monosaccharides, minerals, and organic ions (Figure 4). Multiple copies of genes in the RS JS1-cSAG assembly were annotated as ABC transporters of branched-chain amino acids, dipeptides, oligopeptides, ribose, and xylose. The RS JS1-cSAG had several unique transporters compared to other JS1 genomes, including those for maltose and galactoside (Supplementary Table S7).

\section{Bacterial Microcompartments and Cell Envelope Structure}

Bacterial microcompartments (BMCs) are organelles enveloped with a protein shell that can promote specific metabolic processes by encapsulating and colocalizing enzymes with their substrates and cofactors (Kerfeld et al., 2012; Nobu et al., 2016). Most BMCs share homologous shell proteins while the function of BMCs are different according to the genes adjacent to shell protein genes in BMC gene loci (Axen et al., 2014). The BMC gene loci of the RS JS1-cSAG were compared with those in the Sakinaw Lake SAG co-assembly and BMC genes present in the Sakinaw Lake SAG co-assembly were also found in the RS JS1-cSAG (Supplementary Table S8). In addition to genes encoding the shell proteins, coding sequences for deoxyribosephosphate aldolase and ribose 5-phosphate isomerase were identified adjacent to shell protein genes in BMC gene loci implying that BMCs of the RS JS1-cSAG may be involved in aldehyde and sugar metabolism as suggested by Nobu et al. (2016). Another known feature of Ca. Atribacteria is the diderm cell envelope structure, which has an outer membrane (Dodsworth et al., 2013). HMM search results of proteincoding genes against PFAM databases revealed that some proteins involved in diderm cell structure, such as BamA for outer membrane protein assembly and TolC for type I secretin, were present in the RS JS1-cSAG (Supplementary Table S9).

\section{Central Metabolism and Energy Conservation}

The RS JS1-cSAG possesses genes involved in metabolism to convert various sugars transported into the cytosol via $\mathrm{ABC}$ transporters to pyruvate (Figure 4). Genes encoding $ß$-galactosidase, maltase, and glucosidase that cleave transported oligosaccharides such as galactoside, maltose, and $\alpha$-glucoside into monosaccharides were found. The RS JS1-cSAG also encoded enzymes that convert other monosaccharides such as galactose, ribose and xylose into intermediates in glycolysis. A complete set of genes encoding the enzymes of glycolysis were identified. In addition, the RS JS1-cSAG also encoded enzymes that convert amino acids such as threonine, glycine, serine, and aspartate to pyruvate and vice versa (Supplementary Table S10). The RS JS1-cSAG possesses the potential to convert pyruvate to acetylCoA by pyruvate formate lyase or pyruvate-ferredoxin oxidoreductase reducing ferredoxin. Coding sequences for alcohol dehydrogenase and lactate dehydrogenase suggested lactate and ethanol production through the additional fermentation of pyruvate, using the reducing power generated in glycolysis (Figure 4).

The RS JS1-cSAG encodes the novel syntrophic acetate degradation pathway using tetrahydrofolate (THF) through the glycine cleavage system (Nobu et al., 2015; Figure 4). The RS JS1-cSAG has sequences for pyruvate formate lyase, which condenses acetyl-CoA produced from acetate by acetate kinase with formate to produce pyruvate, and threonine dehydrogenase, which aminates pyruvate to form serine. Genes encoding serine hydroxymethyltransferase, which splits serine into glycine and converts THF to 5,10-methyleneTHF and the enzymes that oxidize 5,10-methylene-THF to yield formate were identified. Coding sequences for formate dehydrogenase $\mathrm{H}(\mathrm{FdhH})$ and membrane-bound hydrogenases (Mbh) A-M, which can oxidize formate to generate $\mathrm{H}_{2}$ 


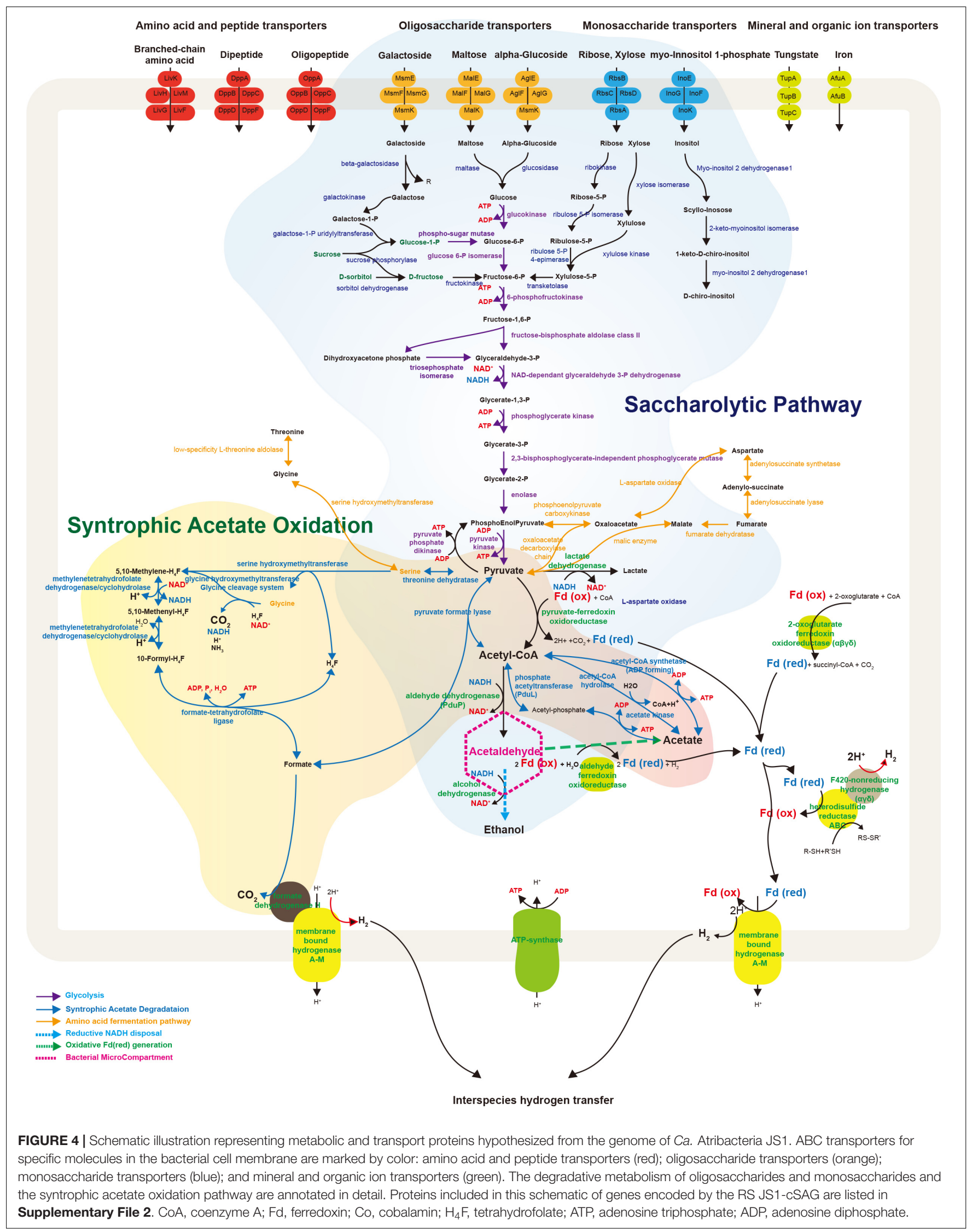




\section{Anoxic sediment}

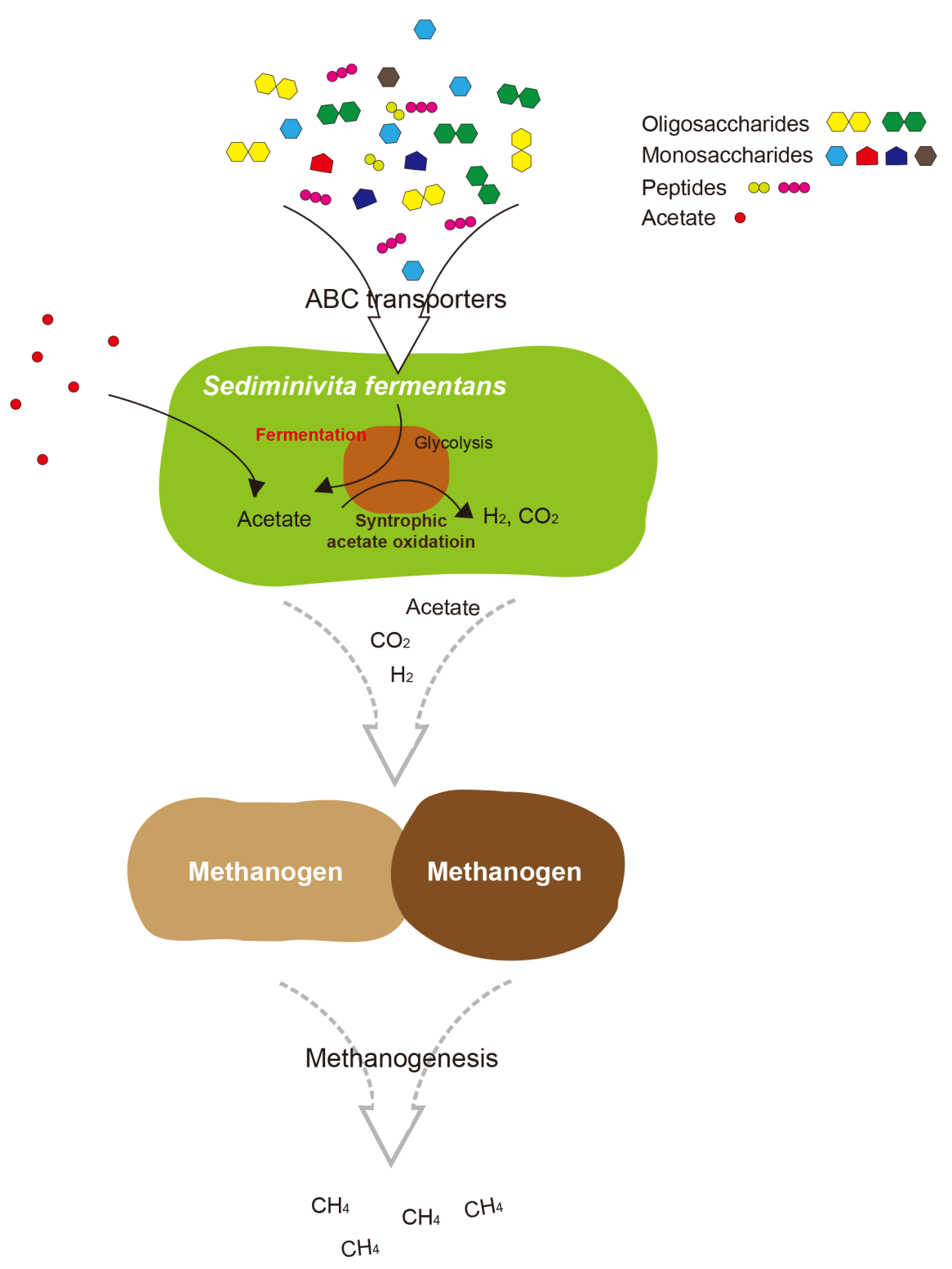

FIGURE 5 | Proposed schematic interactions of Sediminivita fermentans with methanogens and importance in carbon cycling. Sediminivita fermentans ferments pyruvate produced in glycolysis of various amino acids and sugars producing acetate, and also oxidizes acetate producing hydrogen and carbon dioxide via syntrophic association with hydrogen-scavenging methanogens. The resulting acetate, hydrogen and carbon dioxide can support methanogenesis in anoxic sediments.

and $\mathrm{CO}_{2}$, were present in the RS JS1-cSAG. When Mbh extrudes protons outside the membrane for energy conservation, reduced ferredoxin supplies an electron and formate also can be used as an electron donor by FdhH (Figure 4). Electron-bifurcating hydrogenase-like genes encoding F420-nonreducing hydrogenase alpha, delta and gamma subunits, and heterodisulfide reductase ( $\mathrm{Hdr}$ ) genes encoding $\mathrm{HdrABC}$, which may allow hydrogen production were identified in the RS JS1cSAG (Figure 4).

\section{DISCUSSION}

\section{Dominance of Microbial Taxa Frequently Recovered From Methanogenic Environments}

In this study, we observed a clear down-core shift in microbial community composition. In particular, several anaerobic lineages with no cultured representatives, such as Euryarchaeota 
and Lokiarchaeota in archaea and JS1 in bacteria, which have been found in almost methanogenic sediments, were abundant in subsurface sediments. Members of the class Thermoplasmata of Euryarchaeota are known to perform methylotrophic methanogenesis and degrade methylamines via a metatranscriptomic survey (Poulsen et al., 2013). The ecophysiological characteristics and metabolism of members of Lokiarchaeota are not well known owing to a lack of cultured representatives. Sequences belonging to this group have been frequently found in anaerobic and methanogenic sediments, such as gas hydrate-bearing sediments, mud volcanoes, and gas seep, implying that the members of Lokiarchaeota may be closely related to methane cycling (Teske and Sorensen, 2007; Parkes et al., 2014; Ruff et al., 2015). Metagenome sequence of Lokiarchaeota from the sediments near the Loki's Castle hydrothermal vents of the Arctic Ocean revealed that it harbors a complete tetrahydromethanopterin $\left(\mathrm{H}_{4} \mathrm{MPT}\right)$ dependent Wood-Ljungdahl pathway and enzymes revealing the hydrogen dependent potential (Sousa et al., 2016). In addition, in spite of the lack of almost all genes that are specific to methanogenesis, methanogen-like metabolism was suggested by the high similarity of enzymes of $\mathrm{H}_{4} \mathrm{MPT}$ dependent Wood-Ljungdahl pathway to methanogen homologs (Sousa et al., 2016). Members of the JS1 lineage have been recovered frequently from strictly anoxic organic-rich and/or methanogenic environments and specialize in either primary fermentation of carbohydrates or secondary fermentation of organic acids, such as acetate or propionate (Inagaki et al., 2006; Webster et al., 2006a; Blazejak and Schippers, 2010; Orcutt et al., 2011; Gies et al., 2014; Kaster et al., 2014; Parkes et al., 2014; Carr et al., 2015; Nobu et al., 2015, 2016; Oni et al., 2015; Fullerton and Moyer, 2016; Saxton et al., 2016). Methane concentrations were not analyzed in this study and only a few known methanogens (less than 1\%) were observed. Thus, the presence of methane in the study area should be inferred with caution. However, environments where a significant fraction of methane is produced appear to only harbor small fraction of methanogen populations (Inagaki et al., 2006; Gies et al., 2014; Lever, 2016; Carr et al., 2018). Additionally, seismic evidence of gas hydrates and free gas have been reported in the Victoria Land Basin and pockmarks off Franklin Island in the Ross Sea, indicating the potential of subsurface gas release in the study area (Geletti and Busetti, 2011; Lawver et al., 2012). Therefore, the presence of microbial groups frequently found in gas hydrates, organicrich sediments, and other methanogenic environments and seismic surveys seem to suggest the possibility of biogenic methane production in the sediments of the western Ross Sea.

\section{Metabolic Potential Supporting the Predominance of the JS1 Lineage in Methanogenic Marine Environments}

The genomes of JS1 obtained in this study showed $>99.5 \%$ $16 \mathrm{~S}$ rRNA gene similarity with the predominant JS1 OTU throughout the core and formed a monophyletic clade, indicating that these genomes represent the dominant JS1 species of the study area. Because the 18 SAGs obtained in this study were considered to be a single species, a genome, RS JS1cSAG with the most complete JS1 metabolic information within an environment could be obtained by co-assembly of the 18 SAGs. RS JS1-cSAG was classified into "mediumquality" draft genome according to the criteria suggested by Bowers et al. (2017). The genomes in our study showed their highest 16S rRNA gene similarity with that of SCGC AD561-N23 from marine sediment of the Adélie Basin (Carr et al., 2015). While SCGC AD-561-N23 was the first reported JS1 genome from Antarctic marine sediment, its low level of completeness limited the metabolic interpretation and the detailed prediction of in situ ecological functions of the lineage (Carr et al., 2015). However, the high genome completeness of the predominant JS1 species throughout the sediments in this study provides additional insight into the metabolic pathways and fundamental lifestyle of this bacterium in anaerobic sediments. A predominant JS1 species from the Ross Sea (RS JS1) showed metabolic potential for fermentation of pyruvate produced from various sugars and amino acids in anaerobic environments. Further supporting evidence of fermentation, the RS JS1-cSAG was found to harbor ABC transporters for various oligosaccharides, monosaccharides, and amino acids, and enzymes involved in glycolysis and fermentation. In particular, RS JS1-cSAG contained unique ABC transporters for maltose, and additional copies of $\mathrm{ABC}$ transporters for branched-chain amino acids, dipeptides and oligopeptides compared to other JS1 genomes. The presence of coding sequences for various $\mathrm{ABC}$ transporters together with complete gene sets for glycolysis and fermentation seemed to indicate the high potential of RS JS1 to use various substrates to gain energy via fermentation producing $\mathrm{H}_{2}, \mathrm{CO}_{2}$, acetate, and formate as suggested for JS1 genomes from Sakinaw lake, marine sediment of the Adélie Basin, and methanogenic bioreactor (Gies et al., 2014; Carr et al., 2015; Nobu et al., 2015). These products can serve as substrates for methanogenesis and partially explains the importance of fermenters to methanogenic communities (Sieber et al., 2012).

The RS JS1-cSAG also showed the possibility for syntrophic association with hydrogenotrophic methanogens via acetate oxidation. Acetate oxidation, which is thermodynamically unfavorable and thus cannot proceed without hydrogen or formate-scavenging methanogens, can occur through syntrophic association (Hattori, 2008; Stams and Plugge, 2009). The syntrophic acetate-oxidizing bacterium, Pseudothermotoga lettingae strain TMO is suggested to degrade acetate using the THF pathway, whereas Clostridium ultunense strains BS and AOR grow in syntrophic mode with hydrogenotrophic methanogens by running the Wood-Ljungdahl pathway in reverse (Lee and Zinder, 1988; Schnurer et al., 1996; Hattori, 2008). However, the RS JS1-cSAG did not encode carbon monoxide dehydrogenase/acetyl-CoA synthase, the key enzyme that produces an acetyl moiety from the methyl and carbonyl groups, finally producing acetyl-CoA in the Wood-Ljungdahl pathway (Supplementary Figure S4). Consistent with this, carbon monoxide dehydrogenase/acetyl-CoA synthase complex 
has not been identified in other JS1 genomes (Dodsworth et al., 2013; Lloyd et al., 2013; Rinke et al., 2013; Carr et al., 2015; Nobu et al., 2016). Thus, the syntrophic acetate oxidation by running the Wood-Ljungdahl pathway in reverse seems to be unlikely in JS1 bacteria based on their genomic information. Instead, RS JS1 has potential to perform acetate oxidation via a novel syntrophic acetate degradation pathway through the glycine cleavage system in a syntrophic association with hydrogenotrophic methanogens (Nobu et al., 2015). Although correlation results should be interpreted with caution due to the small number of samples compared, Spearman correlation coefficients between the most dominant JS1 OTU and major archaeal OTUs ( $\geq 3 \%$ in relative abundance) were calculated to investigate whether methanogens in this environment are related with JS1 species. One archaeal OTU belongs to Lokiarchaeota, which was mainly found in methanogenic areas such as the Ulleung Basin of the East Sea, the Okhotsk Sea, the Shimokita Peninsula of Japan, and the Gulf of Mexico, showed a covariation pattern with the most dominant JS1 OTU. However, the low $16 \mathrm{~S}$ rRNA gene similarity of the archaeal OTU with sequences of known strains and the lack of most genes that are specific to methanogenesis in the previously known Lokiarchaeota genome (Sousa et al., 2016) made it difficult to infer their potential as hydrogenotrophic methanogens and for syntrophic association with JS1. Hydrogen produced via fermentation of various sugars and amino acids seems to support the correlation between JS1 and hydrogen dependent Lokiarchaeota. In addition, while no correlations with known methanogens of Euryarchaeota were identified in this dataset, considering the presence of phylogenetically widespread methanogens with low similarity of methanogenesis-involved gene sequences as suggested by Lever (2016), it does not rule out that syntrophic relationship between JS1 lineage and unknown methanogens might exist explaining the predominance of the JS1 lineage in methanogenic environments.

The BMCs function both in syntrophic metabolism and sugar or amino acid fermentation by Atribacteria was known from genome analysis (Nobu et al., 2016). In Ca. Caldatribacterium of OP9 lineages and genomes of JS1 lineages from a meromictic lake and bioreactor, NADH produced from sugar oxidation or propionate degradation is consumed by aldehyde dehydrogenase which reduces acetyl-CoA to acetaldehyde within the BMC (Nobu et al., 2016). The RS JS1-cSAG encoded sequences of aldehyde dehydrogenase, supporting the potential for a BMC-associated NADH sink (Supplementary Table S8 and Figure 4). The BMC gene loci of RS JS1 also encoded deoxyribose-phosphate aldolase and ribose 5-phosphate isomerase facilitating aldehyde condensation and storage. Unlike other OP9 and JS1 lineages, the stored carbon within the BMC of the RS JS1-cSAG could be used both for reductive NADH sink via alcohol dehydrogenase, and for oxidative $\mathrm{Fd}_{\text {red }}$ generation, which could allow $\mathrm{H}_{2}$ generation by $\mathrm{Mbh}$ regardless of exogenous substrates through aldehyde:Fd oxidoreductases in the cytosol (Nobu et al., 2016). Thus, BMCs in the RS JS1-cSAG could control sugar fermentation and interact with syntrophic association by facilitating $\mathrm{H}_{2}$ generation via Mbh. This flexibility of carbon storage and later use as an electron sink or source in RS JS1 seems to be advantageous in terms of provision of methanogenic substrates such as hydrogen, $\mathrm{CO}_{2}$, and formate via fermentation of various sugars and amino acids and syntrophic acetate degradation, explaining the predominance of the JS1 lineage in methanogenic environments. Taken together, a hypothetical metabolic process of RS JS1 in anaerobic marine sediment of the Ross Sea is illustrated in Figure 5.

\section{Proposal of Candidatus Sediminivita Fermentans to Refer the Predominant JS1 Species in Marine Sediment of the Ross Sea}

In this study, the most complete JS1 genome to date was obtained from the predominant species in marine sediment of the Ross Sea. Based on the data presented here, we propose the name "Candidatus Sediminivita fermentans" to refer RS JS1. The description of the taxon name is: "Sediminivita" (Se.di.mi.ni.vi'ta. N.L. n. sedimen sediment; L. fem. n. vita life; N.L. fem. n. Sediminivita fermentans) (fer.men'tans. L. part. adj. fermentans fermenting). The genome of Candidatus Sediminivita fermentans revealed metabolic potential as a fermenter using various substrates and a syntrophic acetate oxidizer. Although it is still not clear which lifestyle is predominant in various environments, Candidatus Sediminivita fermentans seems to have the potential for increased survival in nature by using various heterotrophic substrates to outcompete other primary and secondary fermenters, or through syntrophic interactions with partner methanogens. This growth mode may explain the dominance of Candidatus Sediminivita fermentans within anoxic sediments, implying an important ecological function of Candidatus Sediminivita fermentans in carbon cycling.

\section{AUTHOR CONTRIBUTIONS}

YL, SH, SS, HL, and JC conceived and designed the experiments. $\mathrm{YL}$, conducted the experiments for microbial diversity. SH performed the 16S rRNA phylogenetic analysis. YL, KH, $\mathrm{MK}$, and $\mathrm{CH}$ analyzed the pyrosequencing sequences. $\mathrm{KH}$ analyzed the isolation origin. JL and $\mathrm{H}-\mathrm{JN}$ collected and processed the samples. JL and $\mathrm{HC}$ analyzed the environmental data. SS analyzed the single-cell genomes. YL and SS wrote the paper with input and approval by all authors.

\section{FUNDING}

This research was supported by the Korea Polar Research Institute (Grant Nos. PP12020, PE15080, PE18030, PE18080, and PE18090). This work includes contents of YL's thesis 
entitled "Study on the diversity and ecological functions of bacterial communities in the Southern Ocean."

\section{ACKNOWLEDGMENTS}

We thank the captain and crews of RV ARAON for their support at sea. We are very grateful to DongHun Lee at Hanyang University for helpful discussions regarding interpretation of environmental factors and their

\section{REFERENCES}

Axen, S. D., Erbilgin, O., and Kerfeld, C. A. (2014). A taxonomy of bacterial microcompartment loci constructed by a novel scoring method. PLoS Comput. Biol. 10:e1003898. doi: 10.1371/journal.pcbi.1003898

Aziz, R. K., Bartels, D., Best, A. A., Dejongh, M., Disz, T., Edwards, R. A., et al. (2008). The RAST Server: rapid annotations using subsystems technology. BMC Genomics 9:75. doi: 10.1186/1471-2164-9-75

Blazejak, A., and Schippers, A. (2010). High abundance of JS-1- and Chloroflexirelated bacteria in deeply buried marine sediments revealed by quantitative, real-time PCR. FEMS Microbiol. Ecol. 72, 198-207. doi: 10.1111/j.1574-6941. 2010.00838.x

Bowers, R. M., Kyrpides, N. C., Stepanauskas, R., Harmon-Smith, M., Doud, D., Reddy, T. B. K., et al. (2017). Minimum information about a single amplified genome (MISAG) and a metagenome-assembled genome (MIMAG) of bacteria and archaea. Nat. Biotechnol. 35, 725-731. doi: 10.1038/nbt.3893

Carr, S. A., Orcutt, B. N., Mandernack, K. W., and Spear, J. R. (2015). Abundant Atribacteria in deep marine sediment from the Adélie Basin, Antarctica. Front Microbiol. 6:872. doi: 10.3389/fmicb.2015.00872

Carr, S. A., Schubotz, F., Dunbar, R. B., Mills, C. T., Dias, R., Summons, R. E., et al. (2018). Acetoclastic Methanosaeta are dominant methanogens in organic-rich Antarctic marine sediments. ISME J. 12, 330-342. doi: 10.1038/ismej.2017.150

Clarke, K., and Gorley, R. (2006). PRIMER v6: User Manual/Tutorial (Plymouth Routines in Multivariate Ecological Research). Plymouth: Primer-E Ltd.

Corinaldesi, C. (2015). New perspectives in benthic deep-sea microbial ecology. Front. Mar. Sci. 2:17. doi: 10.3389/fmars.2015.00017

Dodsworth, J. A., Blainey, P. C., Murugapiran, S. K., Swingley, W. D., Ross, C. A. Tringe, S. G., et al. (2013). Single-cell and metagenomic analyses indicate a fermentative and saccharolytic lifestyle for members of the OP9 lineage. Nat. Commun. 4:1854. doi: 10.1038/ncomms2884

Edgar, R. C., Haas, B. J., Clemente, J. C., Quince, C., and Knight, R. (2011). UCHIME improves sensitivity and speed of chimera detection. Bioinformatics 27, 2194-2200. doi: 10.1093/bioinformatics/btr381

Eloe-Fadrosh, E. A., Ivanova, N. N., Woyke, T., and Kyrpides, N. C. (2016). Metagenomics uncovers gaps in amplicon-based detection of microbial diversity. Nat. Microbiol. 1:15032. doi: 10.1038/nmicrobiol.2015.32

Felsenstein, J. (1981). Evolutionary trees from DNA sequences: a maximum likelihood approach. J. Mol. Evol. 17, 368-376. doi: 10.1007/BF01734359

Finn, R. D., Coggill, P., Eberhardt, R. Y., Eddy, S. R., Mistry, J., Mitchell, A. L., et al. (2016). The Pfam protein families database: towards a more sustainable future. Nucleic Acids Res. 44, D279-D285. doi: 10.1093/nar/gkv1344

Fullerton, H., and Moyer, C. L. (2016). Comparative single-cell genomics of Chloroflexi from the Okinawa trough deep-subsurface biosphere. Appl. Environ Microbiol. 82, 3000-3008. doi: 10.1128/AEM.00624-16

Geletti, R., and Busetti, M. (2011). A double bottom simulating reflector in the western Ross Sea, Antarctica. J. Geophys. Res 116: B04101. doi: 10.1128/AEM. 00624- 16

Gies, E. A., Konwar, K. M., Beatty, J. T., and Hallam, S. J. (2014). Illuminating microbial dark matter in meromictic Sakinaw Lake. Appl. Environ. Microbiol. 80, 6807-6818. doi: 10.1128/AEM.01774-14

Goris, J., Konstantinidis, K. T., Klappenbach, J. A., Coenye, T., Vandamme, P., and Tiedje, J. M. (2007). DNA-DNA hybridization values and their relationship to whole-genome sequence similarities. Int. J. Syst. Evol. Microbiol. 57, 81-91. doi: 10.1099/ijs.0.64483-0 relationships with microbial communities and Gordon Webster at Cardiff University, United Kingdom for evaluable comments.

\section{SUPPLEMENTARY MATERIAL}

The Supplementary Material for this article can be found online at: https://www.frontiersin.org/articles/10.3389/fmicb. 2018.02909/full\#supplementary-material

Hamdan, L. J., Coffin, R. B., Sikaroodi, M., Greinert, J., Treude, T., and Gillevet, P. M. (2012). Ocean currents shape the microbiome of Arctic marine sediments. ISME J. 7, 685-696. doi:10.1038/ismej. 2012.143

Handelsman, J. (2004). Metagenomics: application of genomics to uncultured microorganisms. Microbiol. Mol. Biol. Rev. 68, 669-685. doi: 10.1128/MMBR. 68.4.669-685.2004

Hattori, S. (2008). Syntrophic acetate-oxidizing microbes in methanogenic environments. Microbes Environ. 23, 118-127. doi: 10.1264/jsme2.23.118

Hugenholtz, P., Pitulle, C., Hershberger, K. L., and Pace, N. R. (1998). Novel division level bacterial diversity in a Yellowstone hot spring. J. Bacteriol. 180 366-376.

Hwang, K., Oh, J., Kim, T.-K., Kim, B. K., Yu, D. S., Hou, B. K., et al. (2013). CLUSTOM: a novel method for clustering 16S rRNA next generation sequences by overlap minimization. PLoS One 8:e62623. doi: 10.1371/journal. pone. 0062623

Inagaki, F., Nunoura, T., Nakagawa, S., Teske, A., Lever, M., Lauer, A. et al. (2006). Biogeographical distribution and diversity of microbes in methane hydrate-bearing deep marine sediments on the Pacific Ocean Margin. Proc. Natl. Acad. Sci. U.S.A. 103, 2815-2820. doi: 10.1073/pnas. 0511033103

Jeon, Y. S., Chung, H., Park, S., Hur, I., Lee, J. H., and Chun, J. (2005). jPHYDIT: a JAVA-based integrated environment for molecular phylogeny of ribosomal RNA sequences. Bioinformatics 21, 3171-3173. doi: 10.1093/bioinformatics/ bti463

Jorgensen, S. L., Hannisdal, B., Lanzén, A., Baumberger, T., Flesland, K. Fonseca, R., et al. (2012). Correlating microbial community profiles with geochemical data in highly stratified sediments from the Arctic Mid-Ocean Ridge. Proc. Natl. Acad. Sci. U.S.A. 109, E2846-E2855. doi: 10.1073/pnas. 1207574109

Kallmeyer, J., Pockalny, R., Adhikari, R. R., Smith, D. C., and D'hondt, S. (2012). Global distribution of microbial abundance and biomass in subseafloor sediment. Proc. Natl. Acad. Sci. U.S.A. 109, 16213-16216. doi: 10.1073/pnas. 1203849109

Kaster, A.-K., Mayer-Blackwell, K., Pasarelli, B., and Spormann, A. M. (2014). Single cell genomic study of Dehalococcoidetes species from deep-sea sediments of the Peruvian Margin. ISME J. 8, 1831-1842. doi: 10.1038/ismej. 2014.24

Kato, C., Li, L., Tamaoka, J., and Horikoshi, K. (1997). Molecular analyses of the sediment of the 11000-m deep Mariana Trench. Extremophiles 1, 117-123. doi: $10.1007 /$ s007920050024

Kerfeld, C. A., Heinhorst, S., and Cannon, G. C. (2012). Bacterial microcompartments. Ann. Rev. Microbiol. 64, 391-408. doi: 10.1146/annurev. micro.112408.134211

Kim, O.-S., Cho, Y.-J., Lee, K., Yoon, S.-H., Kim, M., Na, H., et al. (2012). Introducing EzTaxon-e: a prokaryotic 16S rRNA gene sequence database with phylotypes that represent uncultured species. Int. J. Syst. Evol. Microbiol. 62, 716-721. doi: 10.1099/ijs.0.038075-0

Kurtz, S., Phillippy, A., Delcher, A. L., Smoot, M., Shumway, M., Antonescu, C., et al. (2004). Versatile and open software for comparing large genomes. Genome Biol. 5:R12. doi: 10.1186/gb-2004-5-2-r12

Lane, D. J. (1991). "16S/23S rRNA sequencing," in Nucleic Acid Techniques in Bacterial Systematics, eds E. Stackebrandt, and M. Goodfellow (New York, NY: John Wiley and Sons), 115-175. 
Lawver, L., Lee, J., Kim, Y., and Davey, F. (2012). Flat-topped mounds in western Ross Sea: carbonate mounds or subglacial volcanic features? Geosphere 8, 645-653. doi: 10.1130/GES00766.1

Lee, M. J., and Zinder, S. H. (1988). Carbon monoxide pathway enzyme activities in a thermophilic anaerobic bacterium grown acetogenically and in a syntrophic acetate-oxidizing coculture. Arch. Microbiol. 150, 513-518. doi: 10.1007/ BF00408241

Lee, Y. M. (2017). Study in the Diversity and Ecological Functions of Bacterial Communities in the Southern Ocean. Ph.D. thesis, Seoul National University, Seoul.

Lever, M. A. (2016). A new era of methanogenesis research. Trends Micrbiol. 24, 84-86. doi: 10.1016/j.tim.2015.12.005

Lloyd, K. G., Schreiber, L., Petersen, D. G., Kjeldsen, K. U., Lever, M. A., Steen, A. D., et al. (2013). Predominant archaea in marine sediments degrade detrital proteins. Nature 496, 215-218. doi: 10.1038/nature12033

Macaulay, I. C., and Voet, T. (2014). Single cell genomics: advances and future perspectives. PLoS Genet. 10:e1004126. doi: 10.1371/journal. pgen.1004126

Marshall, I. P., Blainey, P. C., Spormann, A. M., and Quake, S. R. (2012). A singlecell genome for Thiovulum sp. Appl. Environ. Microbiol. 78, 8555-8563. doi: 10.1128/AEM.02314-12

Moriya, Y., Itoh, M., Okuda, S., Yoshizawa, A. C., and Kanehisa, M. (2007). KAAS: an automatic genome annotation and pathway reconstruction server. Nucleic Acids Res. 35, W182-W185. doi: 10.1093/nar/gkm321

Nei, M., and Kumar, S. (2000). Molecular Evolution and Phylogenetics. New York, NY: Oxford University Press.

Nobu, M. K., Dodsworth, J. A., Murugapiran, S. K., Rinke, C., Gies, E. A., Webster, G., et al. (2016). Phylogeny and physiology of candidate phylum 'Atribacteria' (OP9/JS1) inferred from cultivation-independent genomics. ISME J. 10, 273-286. doi: 10.1038/ismej.2015.97

Nobu, M. K., Narihiro, T., Rinke, C., Kamagata, Y., Tringe, S. G., Woyke, T., et al. (2015). Microbial dark matter ecogenomics reveals complex synergistic networks in a methanogenic bioreactor. ISME J. 9, 1710-1722. doi: 10.1038/ ismej. 2014.256

Nunoura, T., Takaki, Y., Shimamura, S., Kakuta, J., Kazama, H., Hirai, M., et al. (2016). Variance and potential niche separation of microbial communities in subseafloor sediments off Shimokita Peninsula. Jpn. Environ. Microbiol. 18, 1889-1906. doi: 10.1111/1462-2920.13096

Oh, J., Kim, B. K., Cho, W.-S., Hong, S. G., and Kim, K. M. (2012). PyroTrimmer: a Software with GUI for pre-processing 454 amplicon sequences. J. Microbiol. 50, 766-769. doi: 10.1007/s12275-012-2494-6

Oni, O. E., Schmidt, F., Miyatake, T., Kasten, S., Witt, M., Hinrichs, K.-U., et al. (2015). Microbial communities and organic matter composition in surface and subsurface sediments of the Helgoland Mud Area, North Sea. Front. Microbiol. 6:1290. doi: 10.3389/fmicb.2015.01290

Orcutt, B. N., Sylvan, J. B., Knab, N. J., and Edwards, K. J. (2011). Microbial ecology of the dark ocean above, at, and below the seafloor. Microbiol. Mol. Biol. Rev. 75, 361-422. doi: 10.1128/MMBR.00039-10

Parkes, R. J., Cragg, B., Roussel, E., Webster, G., Weightman, A., and Sass, H. (2014). A review of prokaryotic populations and processes in sub-seafloor sediments, including biosphere:geosphere interactions. Mar. Geol. 352, 409425. doi: 10.1016/j.margeo.2014.02.009

Parks, D. H., Imelfort, M., Skennerton, C. T., Hugenholtz, P., and Tyson, G. W. (2015). CheckM:assessing the quality of microbial genomes recovered from isolates, single cells, and metagenomes. Genome Res. 25, 1043-1055. doi: 10. 1101/gr.186072.114

Poulsen, M., Schwab, C., Borg Jensen, B., Engberg, R. M., Spang, A., Canibe, N., et al. (2013). Methylotrophic methanogenic Thermoplasmata implicated in reduced methane emissions from bovine rumen. Nat. Commun. 4:1428. doi: $10.1038 /$ ncomms 2432

Richter, M., and Rosselló-Móra, R. (2009). Shifting the genomic gold standard for the prokaryotic species definition. Proc. Natl. Acad. Sci. U.S.A. 106, 1912619131. doi: 10.1073/pnas.0906412106

Rinke, C., Schwientek, P., Sczyrba, A., Ivanova, N. N., Anderson, I. J., Cheng, J.-F., et al. (2013). Insights into the phylogeny and coding potential of microbial dark matter. Nature 499, 431-437. doi: 10.1038/nature12352

Rochelle, P. A., Cragg, B. A., Fry, J. C., Parkes, R. J., and Weightman, A. J. (1994). Effect of sample handling on estimation of bacterial diversity in marine sediments by $16 \mathrm{~S}$ rRNA gene sequence analysis. FEMS Microbiol. Ecol. 15, 215-225. doi: 10.1111/j.1574-6941.1994.tb00245.x

Ruff, S. E., Biddle, J. F., Teske, A. P., Knittel, K., Boetius, A., and Ramette, A. (2015). Global dispersion and local diversification of the methane seep microbiome. Proc. Natl. Acad. Sci. U.S.A. 112, 4015-4020. doi: 10.1073/pnas. 1421865112

Saxton, M. A., Samarkin, V. A., Schutte, C. A., Bowles, M. W., Madigan, M. T., Cadieux, S. B., et al. (2016). Biogeochemical and 16S rRNA gene sequence evidence supports a novel mode of anaerobic methanotrophy in permanently ice-covered Lake Fryxell, Antarctica. Limnol. Oceanogr. 61, S119-S130. doi: 10.1002/lno.10320

Schauer, R., Bienhold, C., Ramette, A., and Harder, J. (2009). Bacterial diversity and biogeography in deep-sea surface sediments of the South Atlantic Ocean. ISME J. 4, 159-170. doi: 10.1038/ismej.2009.106

Schnurer, A., Schink, B., and Svensson, B. H. (1996). Clostridium ultunense sp. nov., a mesophilic bacterium oxidizing acetate in syntrophic association with a hydrogenotrophic methanogenic bacterium. Int. J. Syst. Evol. Microbiol. 46, 1145-1152. doi: 10.1099/00207713-46-4-1145

Sieber, J. R., Mcinerney, M. J., and Gunsalus, R. P. (2012). Genomic insights into syntrophy: the paradigm for anaerobic metabolic cooperation. Ann. Rev. Microbiol. 66, 429-452. doi: 10.1146/annurev-micro-090110-102844

Sousa, F. L., Neukirchen, S., Allen, J. F., Lane, N., and Martin, W. F. (2016). Lokiarchaeon is hydrogen dependent. Nat. Microbiol. 1, 1-3. doi: 10.1038/ nmicrobiol.2016.34

Stams, A. J. M., and Plugge, C. M. (2009). Electron transfer in syntrophic communities of anaerobic bacteria and archaea. Nat. Rev. Microbiol. 7, 568-577. doi: $10.1038 /$ nrmicro2166

Tamura, K., Stecher, G., Peterson, D., Filipski, A., and Kumar, S. (2013). MEGA6: molecular evolutionary genetics analysis version 6.0. Mol. Biol. Evol. 30, 27252729. doi: 10.1093/molbev/mst197

Teske, A., and Sorensen, K. B. (2007). Uncultured archaea in deep marine subsurface sediments: have we caught them all? ISME J. 2, 3-18. doi: 10.1038/ ismej. 2007.90

Webster, G., Parkes, R. J., Cragg, B. A., Newberry, C. J., Weightman, A. J., and Fry, J. C. (2006a). Prokaryotic community composition and biogeochemical processes in deep subseafloor sediments from the Peru Margin. FEMS Microbiol. Ecol. 58, 65-85. doi: 10.1111/j.1574-6941. 2006.00147.x

Webster, G., Parkes, R. J., Fry, J. C., and Weightman, A. J. (2004). Widespread occurrence of a novel division of bacteria identified by $16 \mathrm{~S}$ rRNA gene sequences originally found in deep marine sediments. Appl. Environ. Microbiol. 70, 5708-5713. doi: 10.1128/AEM.70.9. 5708-5713.2004

Webster, G., Sass, H., Cragg, B. A., Gorra, R., Knab, N. J., Green, C. J., et al. (2011). Enrichment and cultivation of prokaryotes associated with the sulphatemethane transition zone of diffusion-controlled sediments of Aarhus Bay, Denmark, under heterotrophic conditions. FEMS Microbiol. Ecol. 77, 248-263. doi: 10.1111/j.1574-6941.2011.01109.x

Webster, G., Watt, L. C., Rinna, J., Fry, J. C., Evershed, R. P., Parkes, R. J., et al. (2006b). A comparison of stable-isotope probing of DNA and phospholipid fatty acids to study prokaryotic functional diversity in sulfate-reducing marine sediment enrichment slurries. Environ. Microbiol. 8, 1575-1589.

Zinger, L., Amaral-Zettler, L. A., Fuhrman, J. A., Horner-Devine, M. C., Huse, S. M., Welch, D. B. M., et al. (2011). Global patterns of bacterial beta-diversity in seafloor and seawater ecosystems. PLoS One 6:e24570. doi: 10.1371/journal. pone. 0024570

Conflict of Interest Statement: The authors declare that the research was conducted in the absence of any commercial or financial relationships that could be construed as a potential conflict of interest.

Copyright (C) 2018 Lee, Hwang, Lee, Kim, Hwang, Noh, Choi, Lee, Chun, Hong and Shin. This is an open-access article distributed under the terms of the Creative Commons Attribution License (CC BY). The use, distribution or reproduction in other forums is permitted, provided the original author(s) and the copyright owner(s) are credited and that the original publication in this journal is cited, in accordance with accepted academic practice. No use, distribution or reproduction is permitted which does not comply with these terms. 